\title{
Nano-SIMS U-Pb zircons dating and geochemistry of from alnöite in Malaita, Solomon Islands
}

\author{
Kouki Kitajima ${ }^{1}$, Akira Ishikawa ${ }^{2}$, Shigenori Maruyama ${ }^{3}$ and Yuji Sano ${ }^{1}$ \\ ${ }^{I}$ Center for Advanced Marine Research, Ocean Research Institute, The University of Tokyo, Tokyo, Japan \\ ${ }^{2}$ Dept. of Earth Sciences, Durham University, Durham, UK \\ ${ }^{3}$ Dept. of Earth and Planetary Sciences, Tokyo Institute of Technology, Tokyo, Japan
}

Kimberlite-hosted zircons commonly occurring as a member of low-Cr megacryst suites have proven useful for $\mathrm{U}-\mathrm{Pb}$ dating which is believed to provide the time of kimberlite eruption, either because of contemporaneous formation, or cooling below the closure temperature of $\mathrm{Pb}$ in zircon (e.g. Davis, 1977; Davis et al., 1976). However, several kimberlite localities are known to have both a contemporaneous and a much older zircon population (e.g. Kinny et al., 1989; Zartman and Richardson, 2005), implying that the quantification of the age distribution is the key to understand the enigmatic origin of the mantle-sourced zircon. The main impediment to obtaining large numbers of age data is the analytical difficulty associated with significantly lower $U$ and radiogenic $\mathrm{Pb}$ contents than crustal zircon, which requires timeconsuming task of digesting relatively large amount of zircons using highly purified chemical reagents in a clean environment. Furthermore, as is the case of crustal zircon, the conventional technique is not suited to reveal more than one history or generation preserved in a given zircon sample. Hence, use of in-situ analysis made by a rapid but precise secondary-ion mass spectrometric (SIMS) technique is a promising approach to detect significantly older age information.

In this study, we apply SIMS U-Pb geochronology and REE geochemistry to zircons separated from an alnöite intrusion, Malaita, Solomon Islands, known as a unique occurrence of low-Cr megacryst suite from an oceanic environment (e.g. Nixon and Boyd, 1979). Although the relationship of megacryst and host alnöite remains unclear, it has been suggested that the alnöite is the end-product of the fractionation process facilitated by the megacryst crystallization (Neal and Davidson, 1989). Two megacrystalline zircons extracted from soils and stream gravels were previously analyzed for $\mathrm{U}-\mathrm{Pb}$ dating by use of conventional technique, and obtained $34 \mathrm{Ma}$ has been interpreted to provide the age of alnöite eruption (Davis, 1977; Davis et al., 1976). However, due to such young, low U ( 4.8 ppm) zircons, the analyses were carried out on large amounts of zircon powders without additional information, thus the aim of this study is to evaluate the previous age data by the use of different technique.

Another aim of this study is to take a broad view of possible age distribution of rare oceanic zircons. Previous studies revealed that the evolutionary history of the lithosphere beneath Malaita includes the Jurassic formation $(\sim 160 \mathrm{Ma})$ of oceanic lithosphere at mid-oceanic ridge setting, and significant disturbance due to Cretaceous ( $\sim 120 \mathrm{Ma})$ Ontong Java Plateau magmatism and subsequent $(\sim 44 \mathrm{Ma})$ minor alkaline basalt magmatism (Ishikawa et al., 2004; Ishikawa et al., 2005; Tejada et al., 1996). Thus, if older generations of zircon are recognized, this may provide potential link between plateau magmatism and megacryst crystallization, or key evidence for existence of crustal heterogeneity within the source of the Ontong Java Plateau (Ishikawa et al., 2007).

\section{Method}

We have separated 110 grains of submillimeter-sized zircon from $1500 \mathrm{~g}$ alnöite rock. Selected 23 grains were subjected to the $\mathrm{U}-\mathrm{Pb}$ isotopic analyses and 11 grains were subjected to the REE analyses performed using CAMECA NanoSIMS 50 at Ocean Research Institute, The University of Tokyo, Japan.

For $\mathrm{U}-\mathrm{Pb}$ dating, intensity of the $\mathrm{O}^{-}$primary ion beam was $\sim 10 \mathrm{nA}$, and the spot size was $10 \mu \mathrm{m}$ in diameter. We got flat-topped peaks with a mass resolving power (MRP) of $\sim 4100$. QGNG standard zircon (1842 Ma) was using for $\mathrm{Pb}^{+} / \mathrm{UO}^{+}$and $\mathrm{UO}_{2}^{+} / \mathrm{UO}^{+}$calibration to obtain ${ }^{238} \mathrm{U}^{206} \mathrm{~Pb}$ ratio. U-Pb age calculation was performed by ISOPLOT v.3, a Microsoft Excel plug-in. Analytical procedures of $\mathrm{U}-\mathrm{Pb}$ isotope dating are outlined in Takahata et al. (2008).

Rare Earth Elements were measured at the same or nearby point of U-Pb dating spot. Spot size was $10 \mu \mathrm{m}$ with $10 \mathrm{nA}$ of $\mathrm{O}^{-}$primary beam. REE, ${ }^{139} \mathrm{La},{ }^{140} \mathrm{Ce}$, ${ }^{141} \mathrm{Pr},{ }^{143} \mathrm{Nd},{ }^{147} \mathrm{Sm},{ }^{151} \mathrm{Eu},{ }^{153} \mathrm{Eu},{ }^{155} \mathrm{Gd},{ }^{157} \mathrm{Gd},{ }^{159} \mathrm{~Tb}$, ${ }^{163} \mathrm{Dy},{ }^{165} \mathrm{Ho},{ }^{167} \mathrm{Er},{ }^{169} \mathrm{Tm},{ }^{174} \mathrm{Yb},{ }^{175} \mathrm{Lu}$ were measured by six magnet scan with multi-collector mode and using energy filter, and also ${ }^{138} \mathrm{Ba}$ and ${ }^{177} \mathrm{Hf}$ were analyzed for interference correction. A $60 \mathrm{~V}$ energy offset was applied to the secondary beam in order to minimize molecular interference. Relative sensitivity factors (RSF) were estimated from QGNG standard zircon analyses (Sano et al., 2002). 


\section{Sample description}

Separated 110 grains of zircon from Malaita alnöite are colorless to honey-yellowish color. Almost all grains have no crystal faces; they are rounded to sub-rounded shapes (Fig. 1). Rounded shapes are common in kimberlite zircon due to resorption in the kimberlite magma (Belousov et al., 1998), and there are no reaction rims. Some zircons, however, preserved a prismatic, euhedral shape (upper left grain of Fig. 1). These lines of evidence suggest that not all grains are fragments of megacrysalline zircon which is commonly discovered from kimberlite. Size of separated zircons is very variable, $350 \mu \mathrm{m}$ to $50 \mu \mathrm{m}$ in length of long axis.

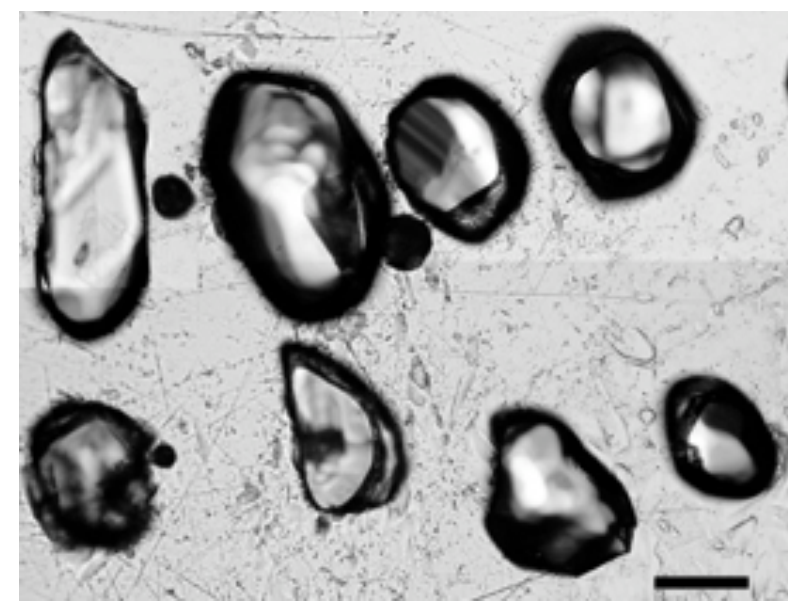

Fig.1. Photomicrograph of Malaita zircons. Scale bar is $100 \mu \mathrm{m}$.

\section{Zircon $\mathrm{U}-\mathrm{Pb}$ isotope ages}

Obtained $23{ }^{238} \mathrm{U}_{-}{ }^{206} \mathrm{~Pb}$ ages from individual grains by NanoSIMS analysis range from 35-49 Ma and yield a weighted mean of $36.9 \pm 0.4 \mathrm{Ma}$ with $\mathrm{MSWD}=1.12$ (Fig. 2). This demonstrates that our results are in agreement with the previous data, despite the slightly older mean value due to the tailing towards older value.

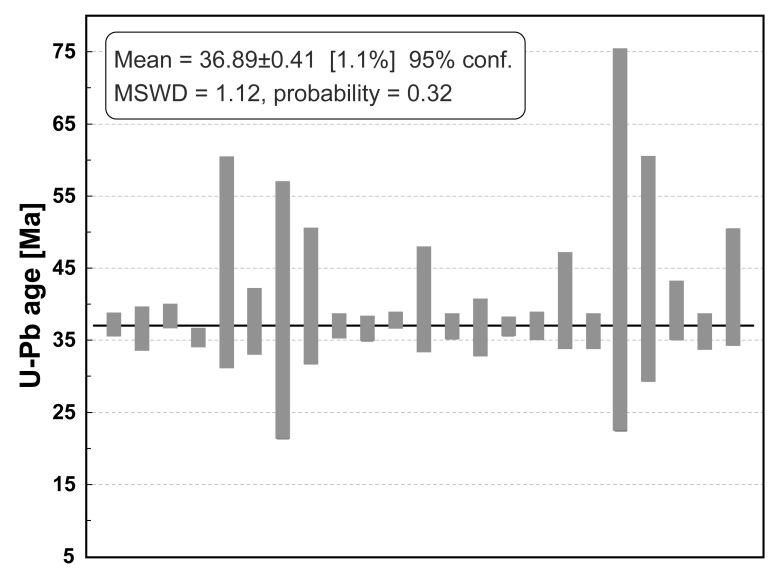

Fig. 2. Weighted mean $\mathrm{U}-\mathrm{Pb}$ ages of zircon from Malaita alnöite. Gray bars display ranges of $\mathrm{U}-\mathrm{Pb}$ ages. Heavy line indicates weighted mean age (36.9 Ma) of 23 analyses. Error bars are $2 \sigma$.

\section{Rare earth elements}

11 grains were selected for REE analysis by NanoSIMS in separate analytical session. The chondrite-normalized REE patterns of the Malaita zircons show variable total REE content and relatively flat heavy and middle REE patterns (Fig. 3). These patterns are similar to range of average compositions of zircon from five cratons (Kaapvaal, Siberia, Alto Paranaiba, Juina and Six-Pak) on four continents. Ratio of chondrite-normalized $(\mathrm{La} / \mathrm{Sm})_{\mathrm{N}}$ ranges from 0.0026 to 0.1614 . Heavy REE shows relatively flat patterns, $(\mathrm{Gd} / \mathrm{Lu})_{\mathrm{N}}=0.0629-0.8360 .(\mathrm{La} / \mathrm{Yb})_{\mathrm{N}}$ displays small variation (0.0002-0.0046). The REE content of Malaita zircons is extremely variable, ranges from $36 \mathrm{ppm}$ to $1058 \mathrm{ppm}$. Some of them are enriched in REE than the kimberlite zircons (Fig. 3). Furthermore, REE content of most kimberlite zircons is less than $50 \mathrm{ppm}$ (Belousov et al., 1998). Low total REE zircons represent the $\mathrm{Nd}$ deficiency which was reported from other low total REE kimberlite zircons (Belousov et al., 1998; Page et al., 2007).

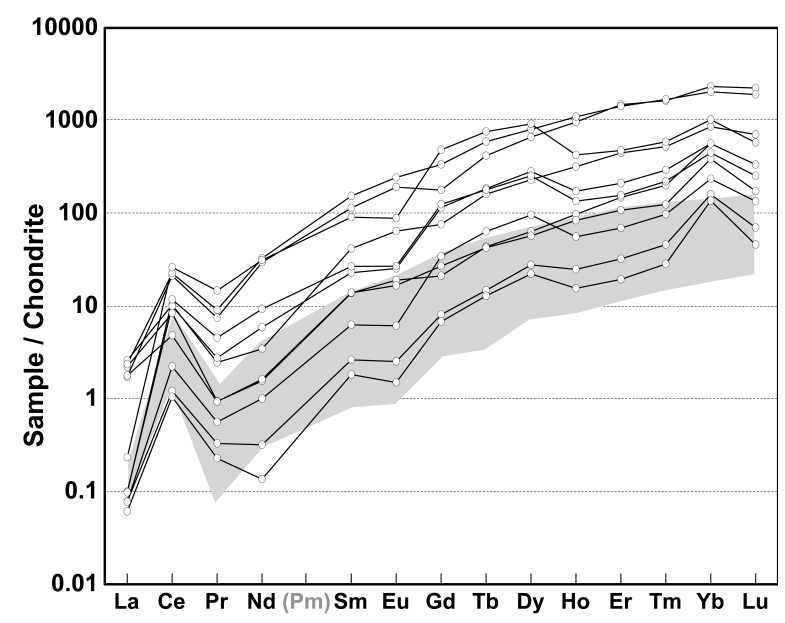

Fig.3. Chondrite-normalized REE patterns of zircons from Malaita alnöite. Shaded area shows the range of average compositions of kimberlite zircons from five cratons on four continents (Page et al., 2007).

\section{Discussion}

Despite the significant error in individual spot analyses, there is a possibility that age variation of the Malaita zircons is varying with their REE concentration (Fig. 4). They can be subdivided into two groups: one is high REE content $(\Sigma$ REE $>300 \mathrm{ppm})$ with younger age $(<38$ $\mathrm{Ma})$; another is low REE content ( $\Sigma \mathrm{REE}<300 \mathrm{ppm})$ with older age $(>38 \mathrm{Ma})$. Alternatively, both groups may follow a single trend on increasing $\Sigma$ REE with decreasing age value. If this correlation is significant, our data may demonstrate that zircon $\mathrm{U}-\mathrm{Pb}$ age reflect the timing of formation rather than temperature-drop due to the host eruption, as suggested for kimberlite zircon based on their low Ti temperatures (Page et al., 2007). In this scenario, the U-Pb ages of zircon record the timing of crystallization from a single evolving magma, whose REE concentrations increased 
temporally. If this is the case, slightly younger age obtained for megacrystalline zircons can be attributed to their crystallization from highly evolved magma. However, more likely explanation is that they resided in significantly deeper mantle than where smaller zircons crystallized. Ti thermometry may prove this possibility.

It is interesting to note that the oldest age obtained in this study is very similar to the eruption age of alkaline basalts [Maramasike Volcanic Formation (MVF): 44 $\mathrm{Ma}$, spatially associated with alnöite intrusions. Based on REE modeling, Neal and Davison (1989) invoked that megacrysts in the Malaita alnöite are the product of crystal fractionation from 'proto-alnöite', which is an alkali basalt character. If it possible that the studied zircons are recording the temporal evolution of the magma stored within the lithospheric mantle beneath the Malaita.

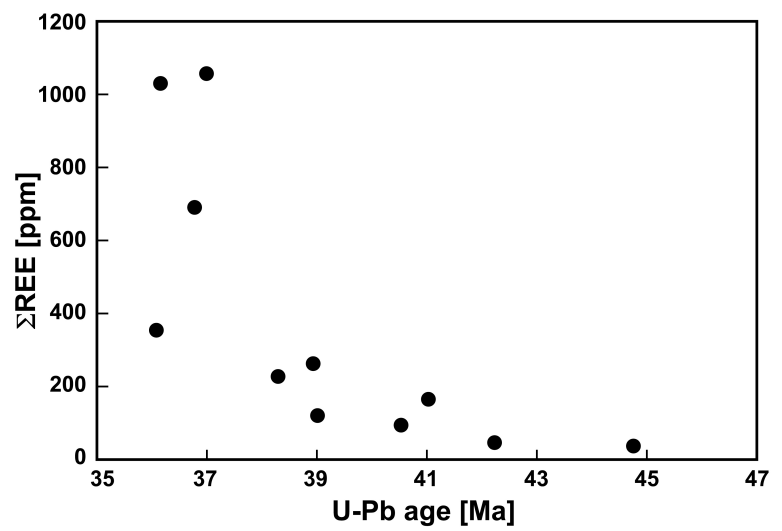

Fig. 4. Relationship between Total REE ( $\mathrm{REE}$ ) concentration and $\mathrm{U}-\mathrm{Pb}$ age of selected Malaita zircon.

\section{Conclusions}

1. We obtained a weighted mean $\mathrm{U}-\mathrm{Pb}$ isotope age of $36.9 \pm 0.4 \mathrm{Ma}$ by ion microprobe (NanoSIMS) from zircon separated from alnöite in Malaita, Solomon Islands. This age is slightly older than previously reported age (34 Ma) for megacrysytalline zircons.

2. Chondrite-normalized REE patterns of alnöite zircons similar to those of continental kimberlite zircons which have flat HREE patterns. Some of alnöite zircons have higher REE concentration, up to $1058 \mathrm{ppm}$ than kimberlite zircons.

3. The correlation between zircon $\mathrm{U}-\mathrm{Pb}$ age and total REE content might reflect temporal evolution of magma that crystallized zircons. This magma is likely to be "proto-alnöite" magma that stored in lithospheric mantle at least between $45 \mathrm{Ma}$ and 36 Ma.

\section{References}

Belousov, E.A., Griffin, W.L., Pearson, N.J., 1998. Trace element composition and cathodoluminescence properties of southern African kimberlitic zircons. Mineralogical Magazine, 62, 355-366.

Davis, G.L., 1977. The age and uranium contents of zircons from kimberlites and associated rock. Extended Abstracts 2nd International Kimberlite Conference, Santa Fe, unpaged.

Davis, G.L., Krogh, T.E., Erlank, A.J., 1976. The ages of zircons from kimberlites from South Africa. Year BookCarnegie Institution of Washington, 75, 821-824.

Ishikawa, A., Kuritani, T., Makishima, A., Nakamura, E., 2007. Ancient recycled crust beneath the Ontong Java Plateau: isotopic evidence from the garnet clinopyroxenite xenoliths, Malaita, Solomon Islands. Earth and Planetary Science Letters, 259, 134-148.

Ishikawa, A., Maruyama, S., Komiya, T., 2004. Layered lithospheric mantle beneath the Ontong Java Plateau: Implications from xenoliths in alnöite, Malaita, Solomon Islands. Journal of Petrology, 45, 2011-2044.

Ishikawa, A., Nakamura, E., Mahoney, J.J., 2005. Jurassic oceanic lithosphere beneath the southern Ontong Java Plateau: evidence from xenoliths in alnöite, Malaita, Solomon Islands. Geology, 33, 393-396.

Kinny, P.D., Compston, W., Bristow, J.W., Williams, I.S., 1989. Archaean mantle xenocrysts in a Permian kimberlite: two generations of kimberlitic zircon in Jwaneng DK2, southern Botswana. In: Ross, J. (Ed.), Kimberlites and Related Rocks. Vol. 2. Their Mantle/Crust Setting, Diamonds and Diamond Exploration. Geological Society of Australia Special Publications, 146, 833-842.

Neal, C.R., Davidson, J.P., 1989. An metasomatized source for the Malaitan alnöite (Solomon Islands): petrogenesis involving zone refining, megacryst fractionation, and assimilation of oceanic lithosphere. Geochimica et Cosmochimica Acta, 53, 1975-1990.

Nixon, P.H., Boyd, F.R., 1979. Garnet bearing lherzolites and discrete nodule suites from the Malaita alnoite, Solomon Islands, S.W. Pacific, and their bearing on oceanic mantle composition and geotherm. In: Boyd, F.R., Meyer, H.O.A. (Eds.), The mantle sample: Inclusions in kimberlite and other volcanics. American Geophysical Union, Washington, 400-423.

Page, F.Z., Fu, B., Kita, N.T., Fournelle, J., Spicuzza, M.J., Schulze, D.J., Viljoen, F., Basei, M.A.S., Valley, J.W., 2007. Zircons from kimberlite: New insights from oxygen isotopes, trace elements, and $\mathrm{Ti}$ in zircon thermometry. Geochimica et Cosmochimica Acta, 71, 3887-3903.

Sano, Y., Terada, K., Fukuoka, T., 2002. High mass resolution ion microprobe analysis of rare earth elements in silicate glass, apatite and zircon: lack of matrix dependency. Chemical Geology, 184, 217-230.

Takahata, N., Tsutsumi, Y., Sano, Y., 2008. Ion microprobe $\mathrm{U}-\mathrm{Pb}$ dating of zircon with a 15 micrometer spatial resolution using NanoSIMS. Gondwana Research, In Press.

Tejada, M.L.G., Mahoney, J.J., Duncan, R.A., Hawkins, M.P., 1996. Age and geochemistry of basement and alkalic rocks of Malaita and Santa Isabel, Solomon Islands, Southern margin of Ontong Java Plateau. Journal of Petrology, 37, 361-394.

Zartman, R.E., Richardson, S.H., 2005. Evidence from kimberlitic zircon for a decreasing mantle $\mathrm{Th} / \mathrm{U}$ since the Archean Chemical Geology, 220, 263-283. 